\title{
Synthesis and Characterisation of a Polysulfone-Polyvinyl Alcohol Hydrogelic Material
}

\author{
Gcineka Mbambisa ${ }^{1}$, Kerileng M. Molapo ${ }^{1}$, Christopher E. Sunday ${ }^{1}$, Christopher Arendse ${ }^{2}$, Priscilla \\ Baker $^{1}$, Emmanuel Iwuoha ${ }^{1 *}$
}

${ }^{1}$ SensorLab, Department of Chemistry and ${ }^{2}$ Department of Physics, University of the Western Cape, Bellville, Cape Town, South Africa

*E-mail: eiwuoha@uwc.ac.za

doi: $10.20964 / 2016.11 .76$

Received: 7 May 2015 / Accepted: 9 August 2016 / Published: 10 October 2016

Hydrogels are flexible materials that have found a niche in membrane science owing to their ability to absorb water without dissolving. The synthesis of polyvinyl alcohol-polysulfone hydrogel in the presence of $N$-hydroxy succinimide is presented herein. This hydrogel is characterised using FTIR spectroscopy, UV-visible spectroscopy, SEM and electrochemical techniques. The FTIR spectroscopic analysis shows that the hydrogel retains bonds that are related to both polysulfone and polyvinyl alcohol moieties. The new hydrogel displays a highly branched morphology with reduced pore size in comparison with polysulfone. The hydrogel also has a lower charge transfer resistance $\left(\mathrm{R}_{\mathrm{ct}}: 12.065 \mathrm{k} \Omega\right)$ in comparison with the polysulfone $\left(\mathrm{R}_{\mathrm{ct}}: 23.260 \mathrm{k} \Omega\right)$, which implies that the hydrogel is more conductive than the original polysulphone.

Keywords: hydrogel, polysulfone, polyvinyl alcohol, cross linker, $N$-hydroxyl succinimide

\section{FULL TEXT}

(C) 2016 The Authors. Published by ESG (www.electrochemsci.org). This article is an open access article distributed under the terms and conditions of the Creative Commons Attribution license (http://creativecommons.org/licenses/by/4.0/). 